\title{
Design and Validation of Multidimensional Hybrid Metamaterial Embedded Light Trapping Structure for p-Si/n-ZnO Based Thin c-Si Solar Cell
}

Arijit Bardhan Roy ( $\square$ arijitbardhanroy@mits.ac.in )

Madanapalle Institute of Technology \& Science

\section{Research Article}

Keywords: light trapping structure, multidimensional material, metamaterials

Posted Date: July 12th, 2021

DOl: https://doi.org/10.21203/rs.3.rs-667147/v1

License: (c) (1) This work is licensed under a Creative Commons Attribution 4.0 International License.

Read Full License 


\section{Abstract}

This paper deals with one competent light trapping structure of metamaterials embedded $\mathrm{p}-\mathrm{Si} / \mathrm{n}$-ZnO based thin solar cell assisted by different simulation studies. Through this article, author exposed the credibility of $\mathrm{ZnO}$ as multidimensional material with dual utility to serve as anti reflective coating with active material of this hetero-junction solar cell. Additionally, dielectric metamaterial like silica nanoparticles on top of the structure enhanced the photon cultivation efficiency of the device. Further through this work try to validate the simulated structure in real world by the process of simple fabrication technique which also offer same optical responses already given by theoretical studies. This investigation also confirms the metamaterial property of the monolayer silica nanopartcles in higher angle of incidence of light which validate its utility in solar cell where injection of photon was needed throughout the day. During the analysis of electric field and reflectance profiles generated by mentioned light trapping structure, it is very recognizable that, in future this type of hybrid structure which is combination of semiconductor with metamaterials will make solar cell more efficient and cost effective.

\section{Introduction}

For the fulfilment of future energy demand as well as to protect green future for saving our earth from environmental calamity it is of extern importance to focus our research on non-conventional energy. Therefore, the importance of solar photovoltaic (PV) technology is one of the major aspects in the present world. Though the different types of approaches have been adopted by recent PV technology, but due to better stability with high efficiency of c-Si solar cells still dominate the market. But the major disadvantage of this c-Si technology is due to its high raw material (silicon) cost. Though Shockley already mentioned more than fifty years back regarding the optimum thickness of silicon, but industries are still using $180 \mu \mathrm{c}$ thick absorber layer [1-7]. Now it is high time to promote thin c-Si wafers (20-30 $\mu \mathrm{c}$ substrate) to reduce the material cost of silicon solar cell to reduce the current market price of solar cell. Keeping this in mind, again all the industries and $R$ \& D sectors must focus on low processing technology with conventional materials can also make solar cell more popular as a prime source in power sector. As a result, the multidimensional material like $\mathrm{ZnO}$ which have dual quality like $\mathrm{n}$ type absorbing semiconductor with antireflective property promotes its importance in solar cell research community.

In this work author try to present a modelling of heterojuntion solar cell with $\mathrm{p}$ type thin c-Si with n-type $\mathrm{ZnO}$ embedded with loss less dielectric nanoparticles (silica) on top of this heterojunction device which is at as treated as hybrid light trapping structure made of semiconductor ( $\mathrm{ZnO})$ and metamaterial (silica). During this simulation study, it was determined that silica nanoparticles able to enhance the photon injection into the solar cell through scattering of light not just in zero-degree angle of incidence, but it will also capable in giving better result in wider angle of occurrence also. At last, through simple fabrication technique attempt to validate the simulated geometries in real world and try to give practical authentication of the study.

\section{Optical Simulation And Analysis}




\subsection{Simulation setup and material selection}

To establish the significance of heterojunction-based silicon solar cell with silica nanoparticles, go through some optical simulations. Simulation model was developed with the assist of FEM based solver due to sub wavelength / wavelength scale geometry. Fig-1 shows the simulation setup adopted for the present work. The periodic boundary conditions are used on both sides of heterojunction structure. The monolayers of silica nanoparticles were embedded on top of the ZnO layer to establish the necessity of silica nanoparticles as light trapper. To perform the optical simulation, need to introduce two ports, one is on the top and another is bottom of the structure. The optical structure receives the light energy through port 1. A perfect electric contact (PEC) connected in port two to validate the structure for practical solar cells which are available in the market and measure the response of reflection and transmission of light through the structure. The refractive indexes of different materials are taken from previous studyC [7].

The optimization of the thickness for the $\mathrm{ZnO}$ layer already established by some previous reports. So, in this work mostly concentrated on $5 \mu \mathrm{m} \mathrm{ZnO} \mathrm{layer} \mathrm{on} 30 \mu \mathrm{m}$ c-Si substrate. The diameter of $300 \mathrm{~nm}$ silica nanoparticle was chosen due to its optimum refractive index (1.27) lies between the refractive indexes offered by $\mathrm{ZnO}$ (1.5-2.5) and Air (1). Through the previous studies it was already established the light trapping capability of multilayer silica nanoparticles. But further due decreasing the material cost adopted by simple fabrication method, monolayer of silica nanoparticles on top of the heterojunction solar cell was investigated through this work [8].

\subsection{Optical study of $\mathrm{p}-\mathrm{Si}$ and $\mathrm{n}-\mathrm{ZnO}$ based heterojunction solar cell}

Fig. 2 shows the electric field profile of $30 \mu \mathrm{m}$ thin silicon with $5 \mu \mathrm{m} \mathrm{ZnO}$ on zero degree incidence of light taken from $400 \mathrm{~nm}$ to $700 \mathrm{~nm}$ wavelengths. In this picture it was clearly observed that due to matching of refractive indexes between silicon (3.34) and $\mathrm{ZnO}$ (1.5-2.5) layer, more photon was injected into the heterojunction in the visible wavelengths. This study established the acceptance of the importance of $\mathrm{ZnO}$ material not just as n-type material of solar cell but also treated as ARC (anti reflection coating) of this heterojunction structure. Not just in the visible light region this phenomenon is also observed (Fig. 3) in near infrared and infrared wavelength a region (800-1100 $\mathrm{nm}$ region) which is more dominating compared to first one [9-16].

\subsection{Optical study of $\mathrm{p}-\mathrm{Si}$ and $\mathrm{n}-\mathrm{ZnO}$ based heterojunction solar cell embedded with silica nanoparticles on zero degree incidence of light:}

Fig. 4 and 5 shows the electric field profile of silica nanoparticles (Si NPs) embedded Si-ZnO based heterojunction structure for thin silicon solar cell on different angle of incidence of light (400 nm to $1100 \mathrm{~nm}$ ). Both the figures clearly indicate the photon harvesting capability of Silica NPs into the junction of solar cell. The Silica NPs offers the multiple scattering of light rays into the structure. As a result, the path lengths of the light rays increase immensely. Therefore, formation of the multiple hotspots was seen into the junction which was schematically shown in Fig.1. Another fact must be considered that the 300 $\mathrm{nm}$ silica naoparicle offers the refractive index of 1.27 (approx) which is greater than Air and less than 
ZnO. So refractive index matching was perfectly done in the structure. As all knows that the silica nanopartcles have the loss less dielectric property so it has high possibility of contributing the whispering Gallery effect by these nanoparticles. These types of light trapping properly of silica nanoparticles were not just observed in the only visible wavelength regions (shown by Fig. 4) but also noticed in near infrared and infrared region also which was validated by Fig. 5. In this structure $\mathrm{ZnO}$ is treated as multipurpose material (both as absorber and ARC) therefore, the electron hole pairs generated into the $\mathrm{ZnO}$ layer also contribute to produce the short circuit current of proposed heterojunction solar cell.

\subsection{Optical study of p-Si and n-ZnO based heterojunction solar cell embedded with silica nanoparticles on 45 degree incidence of light :}

Fig. 6 and 7 shows the electric field profiles of silica embedded p-Si/ZnO based heerjunction structures in different wavelength regions under 45-degree incidence of light. To investigate both the figures (Fig. 6 and 7) it can quite clear that in higher angle of incidence light, the silica nanoparticles act as metamaterial Mie resonators which have better ability to harvest more photons into the junction compared to previous two cases. The monolayer of silica nanoparticles has the capacity to bend light rays more proficiently like negative indexed metamaterial which produce better results with more hotspots that is very near to the junction of the device $[8,17]$. So, it is quite evident that, this type of device structure shows better competent to inject more photons into the device in the higher angle of light compared to zero degree incidence. This quality of the device supports its utilization as solar cell which must have the supremacy to produce maximum power from sun throughout the day. This fact is also validated by the reflectance profiles shows by Fig. 8 .

\section{Fabrication Method:}

However, in this work we are mainly focused on electrochemical deposition process. In earlier Mukherjee et al already deposited $\mathrm{ZnO}$ thin films on p-type Si wafers [18]. In this process $30 \mu \mathrm{c}$ silicon wafers have been achieved by chemical etching process. Then the wafers are cleaned by $10 \% \mathrm{HCl}$ solution for $2-3$ hours in $80^{\circ} \mathrm{C}$ and at last dipped in $10 \% \mathrm{HF}$ solution for 5 minutes. The electrolyte is prepared by $0.1 \mathrm{M}$ ZnSo4 solution. A Zn rod (99\%) with a p-Si wafer is dipped into the solution and both are well connected by a Cu wire. In this method $\mathrm{Zn}$ rod treated as anode as well as Si wafer served as cathode for self decaying purpose. The $\mathrm{pH}$ of the solution maintained between 4 to 5 for uniform $\mathrm{ZnO}$ deposition. No external temperature is needed for the reaction.

Further for more photon transmitted in the junction the mono layer of silica nanoparticles embedded on top surface of the device which may treat as ARC coating of the cell. The silica nanoparticles are synthesized by modified stober method and embedded by spin coating technique [8]. The FESEM image of synthesized on top of the thin silicon surface is shown in Fig. 9. 


\section{Reflectance:}

Reflectance measurements of fabricated nanoparticles embedded thin silicon wafers were done by Bentham PVE300 spectrometer with integrated sphere and the characteristics are presented in Fig.10. It is quite perceptible from the reflectance data that the synthesized silica nanoparticles with ZnO layer can successfully offer low reflectance and can bring in maximum photon into the silicon substrate very capably in comparison to the bare monocrystalline ultrathin wafer prepared in this study.

\section{Conclusion:}

In this study, author tries to validate the light trapping structure offered by $\mathrm{ZnO}$ layer embedded with monolayer of silica nanoparticles. As per the knowledge, it was revealed the negative refractive index property of monolayer silica nanoparticles on higher angle of incidence of light for the first time. Not only that, through this work it also proved the utilization of $\mathrm{ZnO}$ as multipurpose material which may be able to serve ARC coating as well as active material of solar cell. Lastly, at the end of this study author strongly believed that this work will motivate the future researchers to hit upon more practice of metamaterials and multidimensional materials in solar cell production sector which may be capable to reduce the processing and material cost of PV device without compromising its efficiency.

\section{Declarations}

\section{Acknowledgements:}

The authors would like to acknowledge the Department of Electrical and Electronics Engineering (Madanapalle Institute of Technology \& Science), India for the financial and infrastructural support.

\section{References}

[1]. S. Das, A. Kundu, H. Saha and S. K. Datta et al 2015 Plasmonics. 10189.

[2] D. Kar and D. Das et al 2013 Journal of Materials Chemistry A. 114744.

[3] J. H. Lee, J. Kim, T. Y. Kim, M. S. A. Hossain, S. W. Kim and J. H. Kim et al 2016 Materials Horizons 3 7983.

[4] M. Saifullah, J. Gwak and J. H. Yun et al 2016 Journal of Materials Chemistry A 48512.

[5] R. Li, J. Di, Z. Yong, B. Sun and Q. Li et al 2014 Journal of Materials Chemistry A. 24140.

[6] W. Shockley and H. J. Queisser et al 1961 Journal of Applied Physics. 32510.

[7] A. B. Roy, A. Dhar, M. Choudhuri, S. Das, S M Hossain and A. Kundu et al 2016 Nanotechnology. 27305302. 
[8] A. B. Roy, S. Das, A. Kundu, C. Banerjee and N. Mukherjee et al 2017 Physical Chemistry Chemical Physics. 1912838.

[9] B. Hussain, A. Ebong and I. Ferguson et al 2015 Solar Energy Materials and Solar Cells. 5516.

[10] A. Kim, Y. Won, K. Woo, C. Kim and J. Moon et al 2013 ACS Nano. 71081.

[11] Y. Lee, M. Choi, D. Kim, C. Kim, M. Song, J. Kang, Y. Jeong, K. Nam, S. Park, S. Kwon, S. Y. Ryu and J. Kwon et al 2012 Journal of Physical Chemistry. C. 11623231.

[12] C. Ko, Y. Han, C. Chen, J. Shieh and M. Chen et al 2013 Journal of Physical Chemistry. C. 11726212.

[13] J. Yoo, X. Ma, W. Tang and G. Yi et al 2013 Nano Letters. 132134.

[14] B. Niesen, N. Blondiaux, M. Boccard, M. Stuckelberger, R. Pugin, E. Scolan, F.Meillaud, F. Haug, A. Hessler-Wyser and C. Ballif et al 2014 Nano Letters. 145085.

[15] K. Mahmood, S. B. Park and H. J. Sung et al 2013 Journal of Materials Chemistry. C. 1, 3138.

[16] N. Park, K. Sun, Z. Sun, Y. Jing and D. Wang et al 2013 Journal of Materials Chemistry. C.1, 7333.

[17] J. Grandidier, D. M. Callahan, J. N. Munday and H. A. Atwater et al 2012 IEEE J. Photovoltaics 2123.

[18] N Mukherjee, P Bhattacharyya, M Banerjee, A Mondal, Robert T T Gettens, P K Ghosh and H Saha et al 2006 Nanotechnology 172665.

\section{Figures}




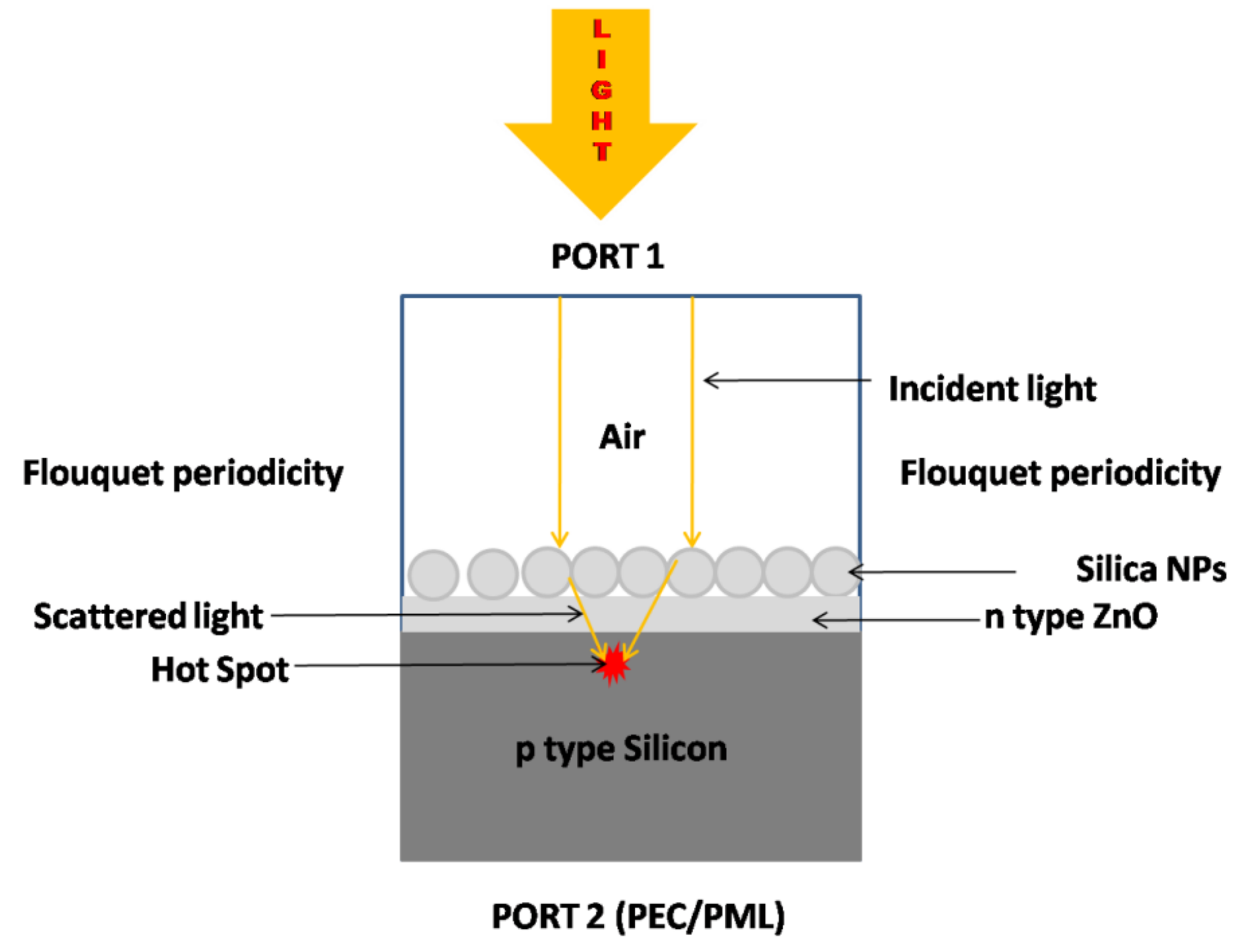

Figure 1

Proposed device structure and simulation model. 


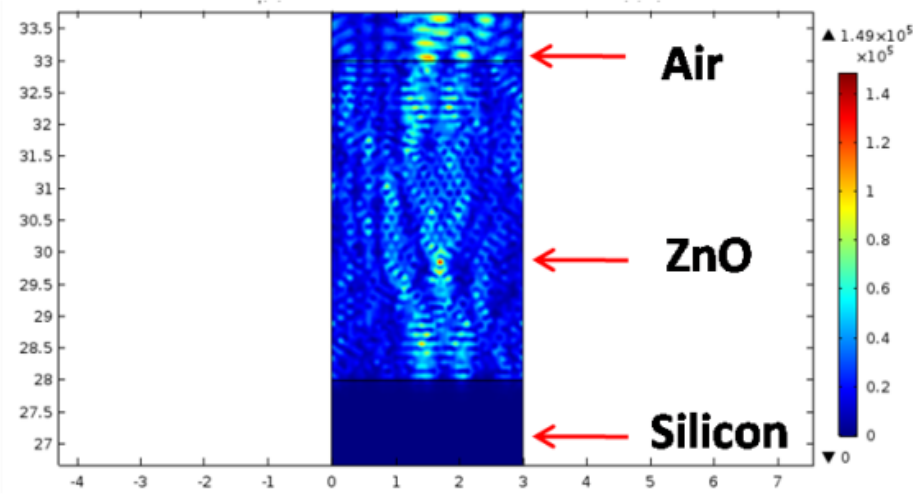

$400 \mathrm{~nm}$

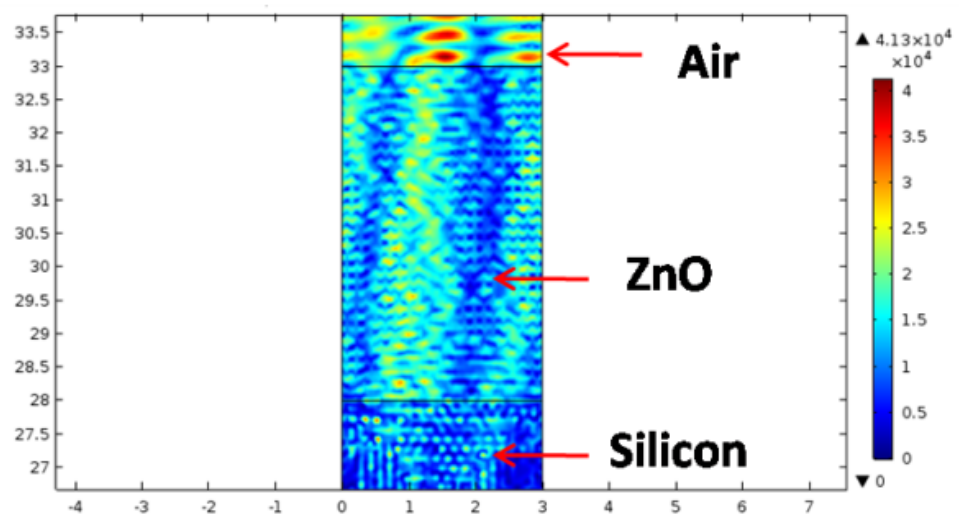

$600 \mathrm{~nm}$
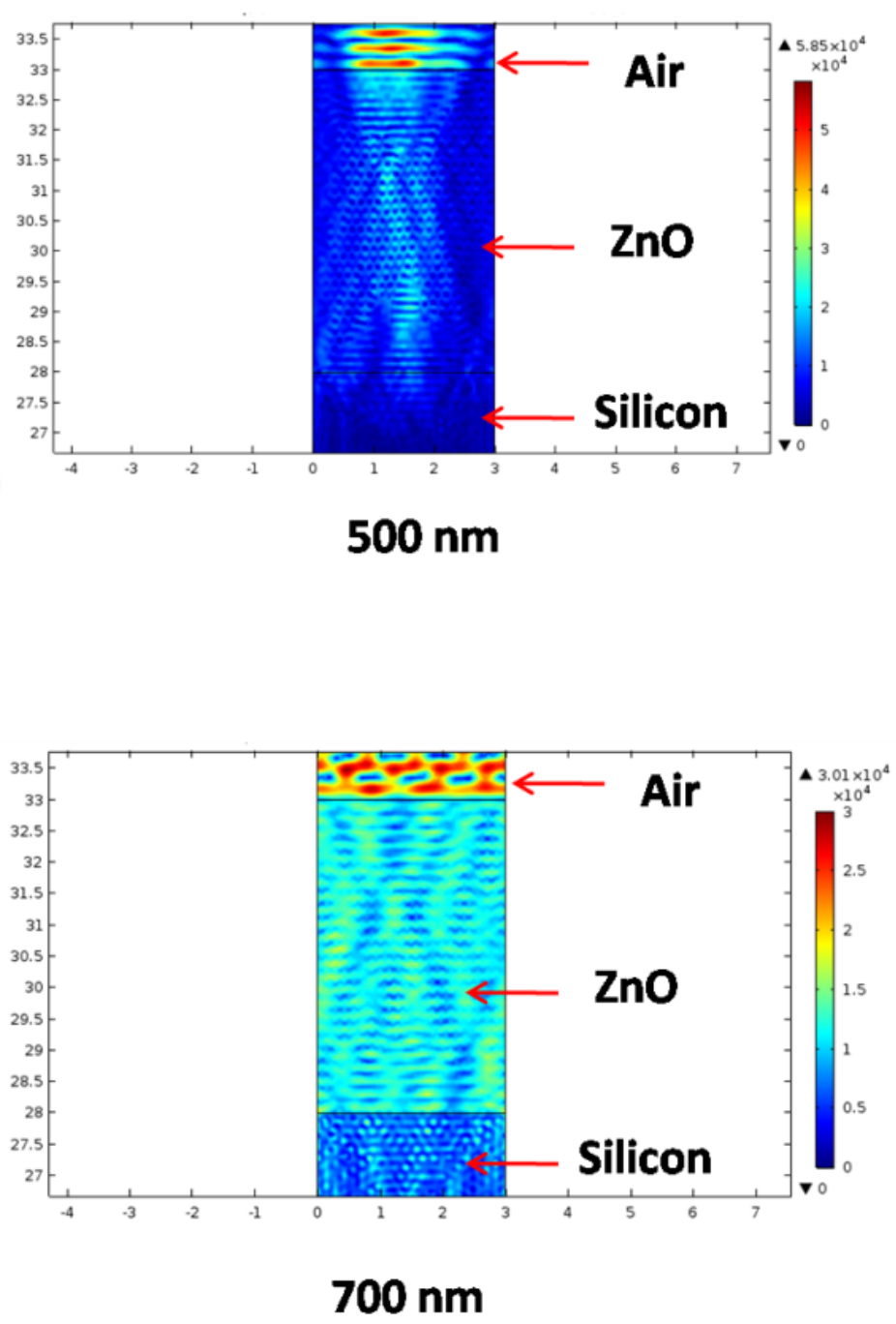

Figure 2

Electric field distribution along air/ZnO/Si at wavelengths $400 \mathrm{~nm}, 500 \mathrm{~nm}, 600 \mathrm{~nm}$ and $700 \mathrm{~nm}$ for $0^{\circ}$ angle of incidence. 

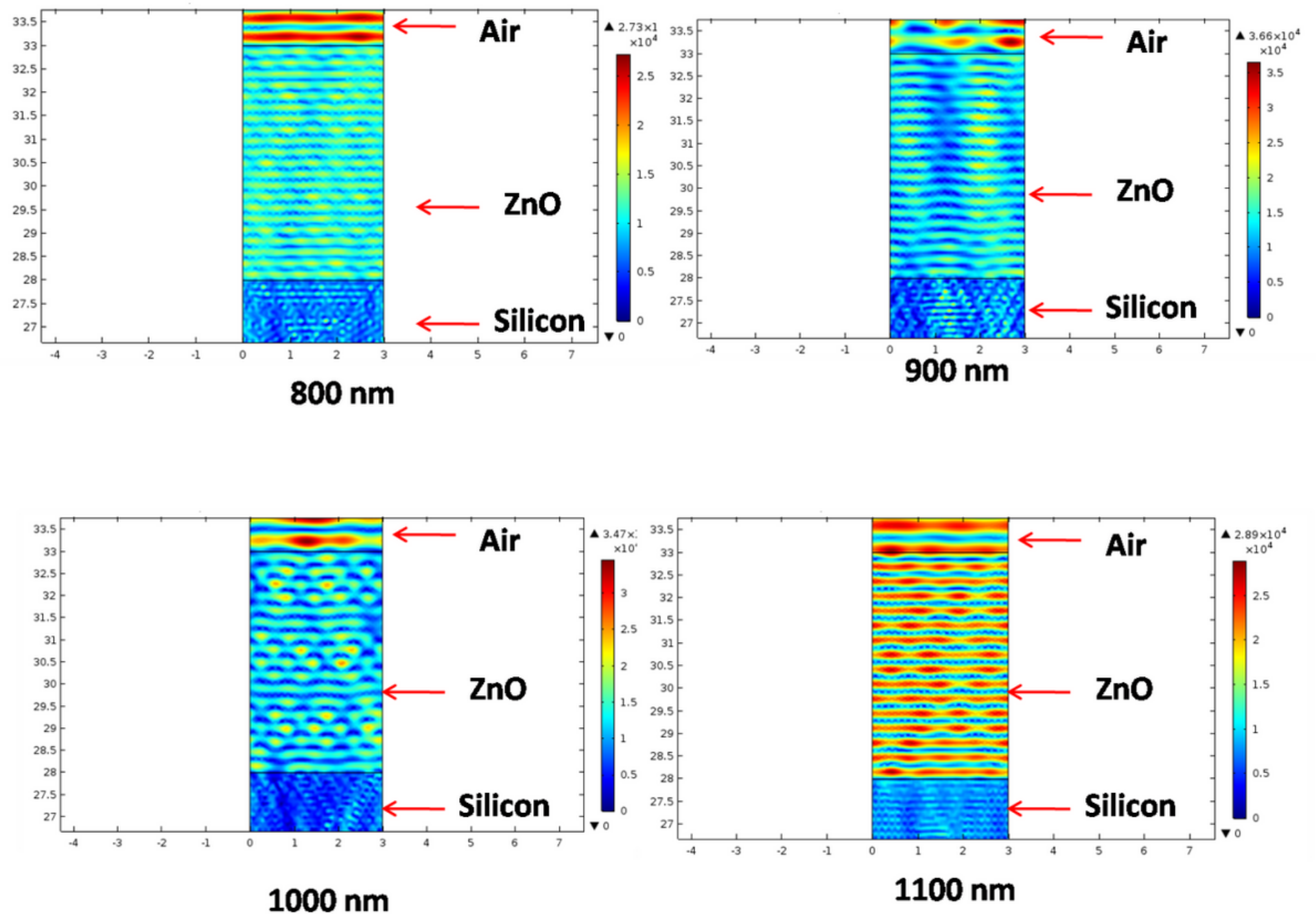

Figure 3

Electric field distribution along air/ZnO/Si at wavelengths $800 \mathrm{~nm}, 900 \mathrm{~nm}, 1000 \mathrm{~nm}$ and $1100 \mathrm{~nm}$ for $0^{\circ}$ angle of incidence. 

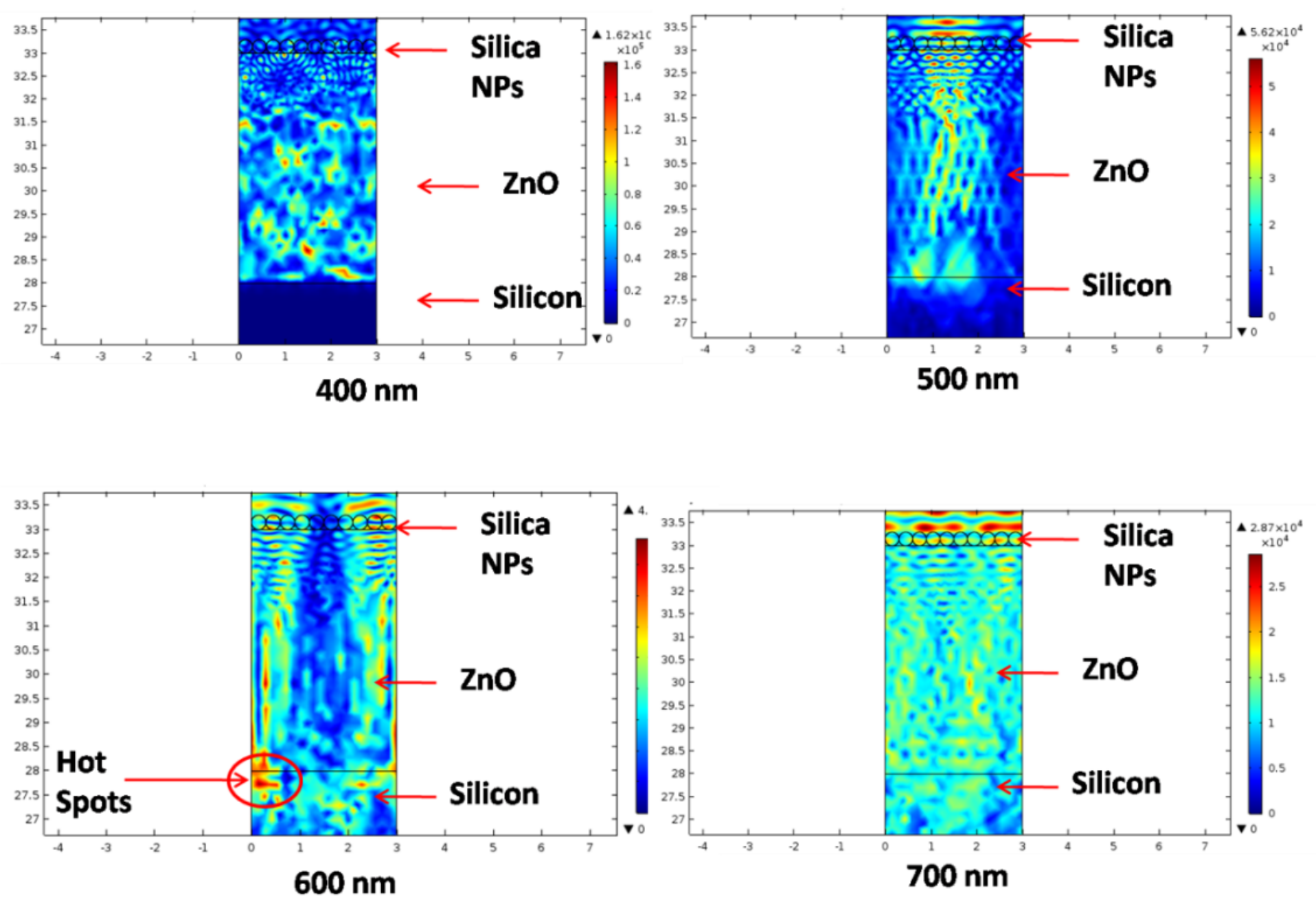

Figure 4

Electric field distribution along air/silica/ZnO/Si at wavelengths $400 \mathrm{~nm}, 500 \mathrm{~nm}, 600 \mathrm{~nm}$ and $700 \mathrm{~nm}$ for $0^{\circ}$ angle of incidence. 

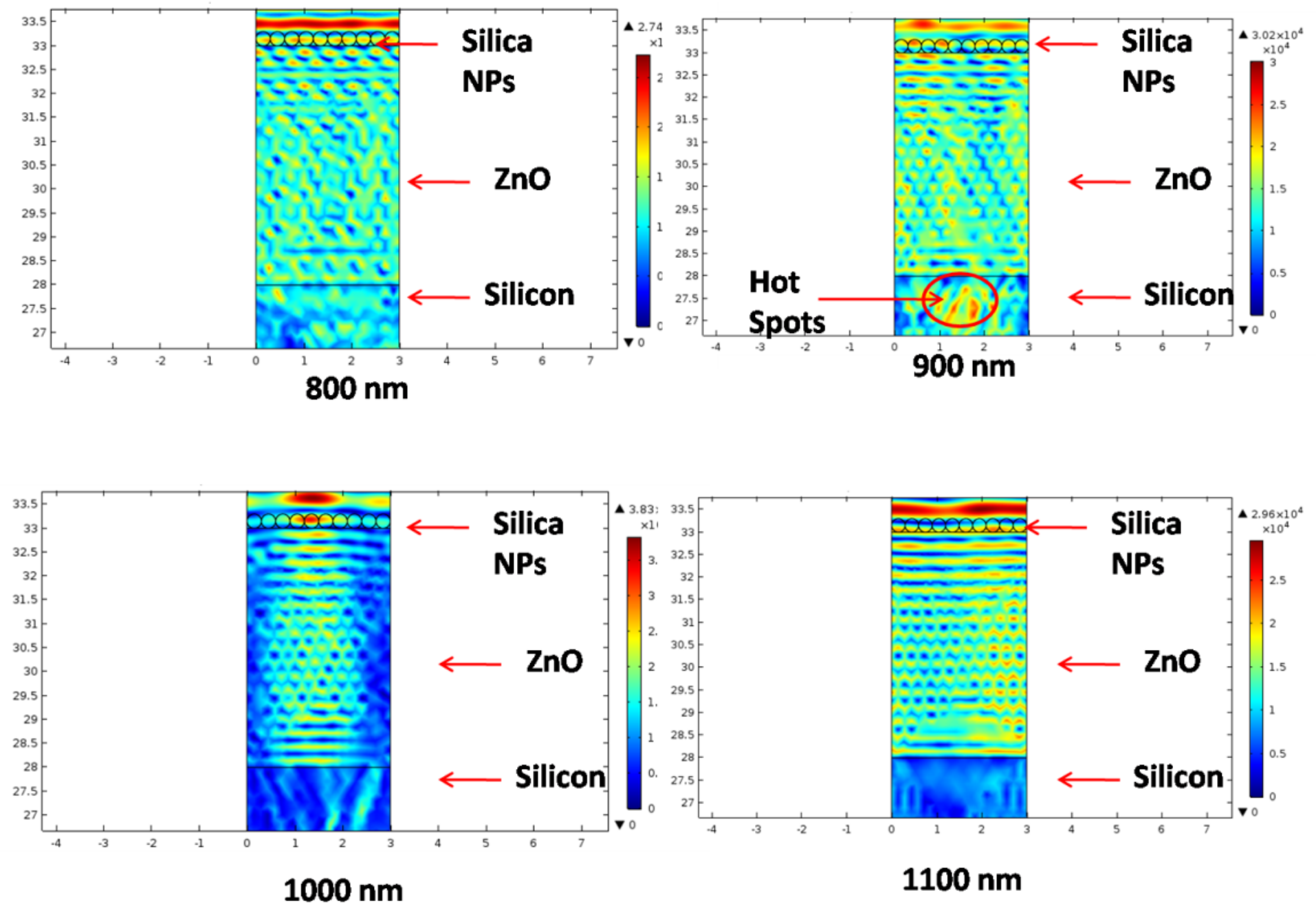

Figure 5

Electric field distribution along air/ZnO/Si at wavelengths $800 \mathrm{~nm}, 900 \mathrm{~nm}, 1000 \mathrm{~nm}$ and $1100 \mathrm{~nm}$ for $0^{\circ}$ angle of incidence. 

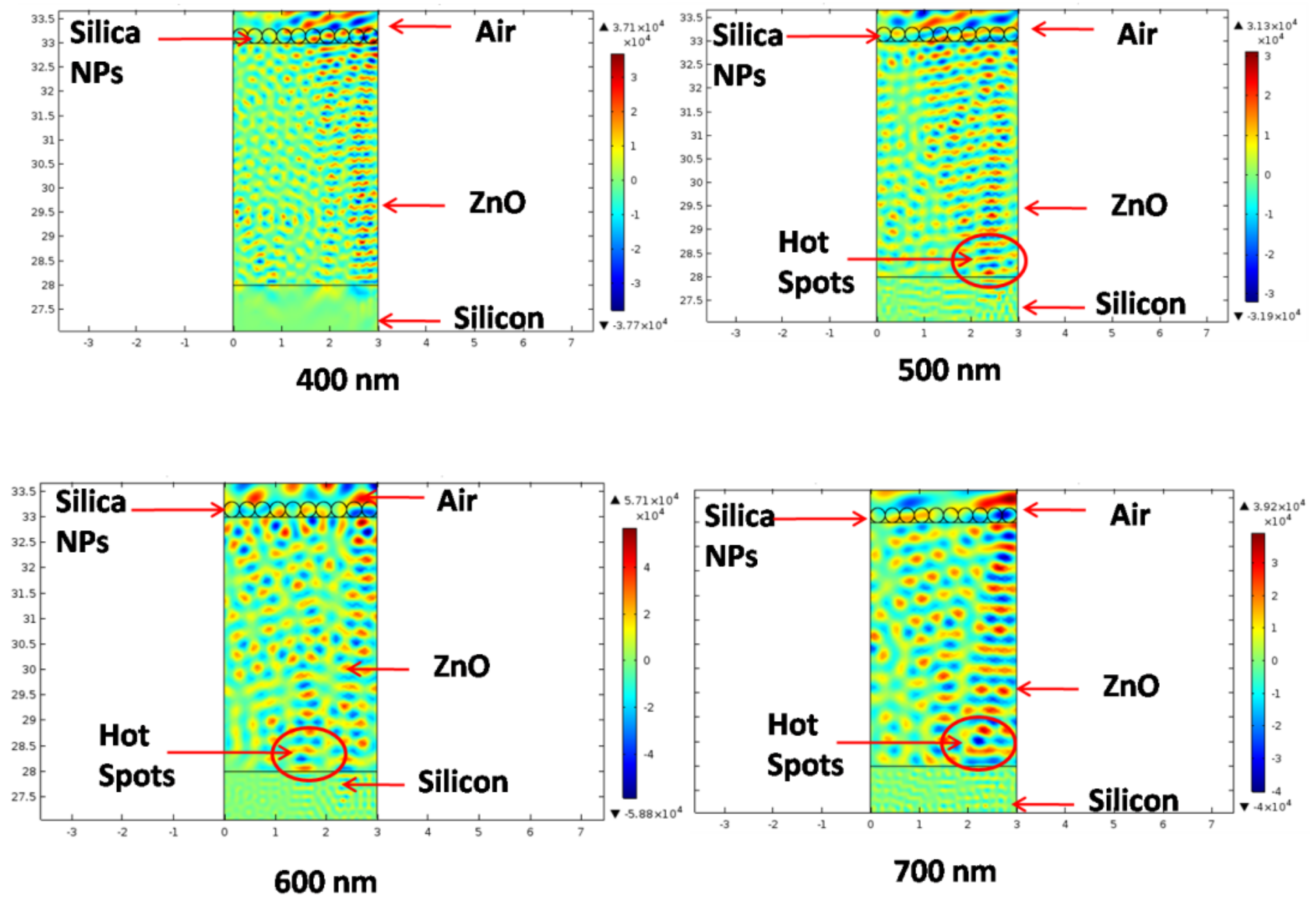

Figure 6

Electric field distribution along air/silica/ZnO/Si at wavelengths $400 \mathrm{~nm}, 500 \mathrm{~nm}, 600 \mathrm{~nm}$ and $700 \mathrm{~nm}$ for $45^{\circ}$ angle of incidence. 

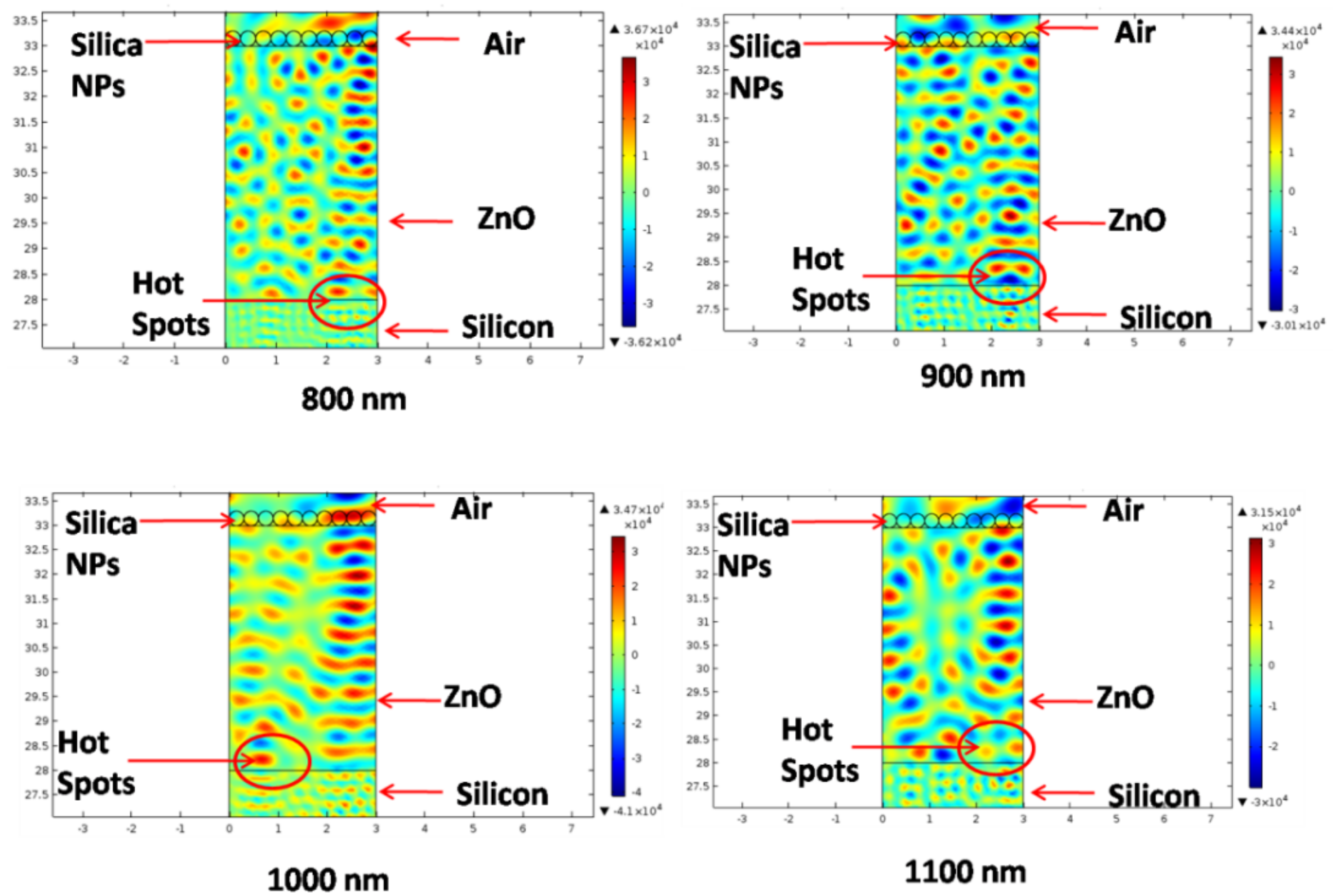

Figure 7

Electric field distribution along air/silica/ZnO/Si at wavelengths $800 \mathrm{~nm}, 900 \mathrm{~nm}, 1000 \mathrm{~nm}$ and $1100 \mathrm{~nm}$ for $45^{\circ}$ angle of incidence. 


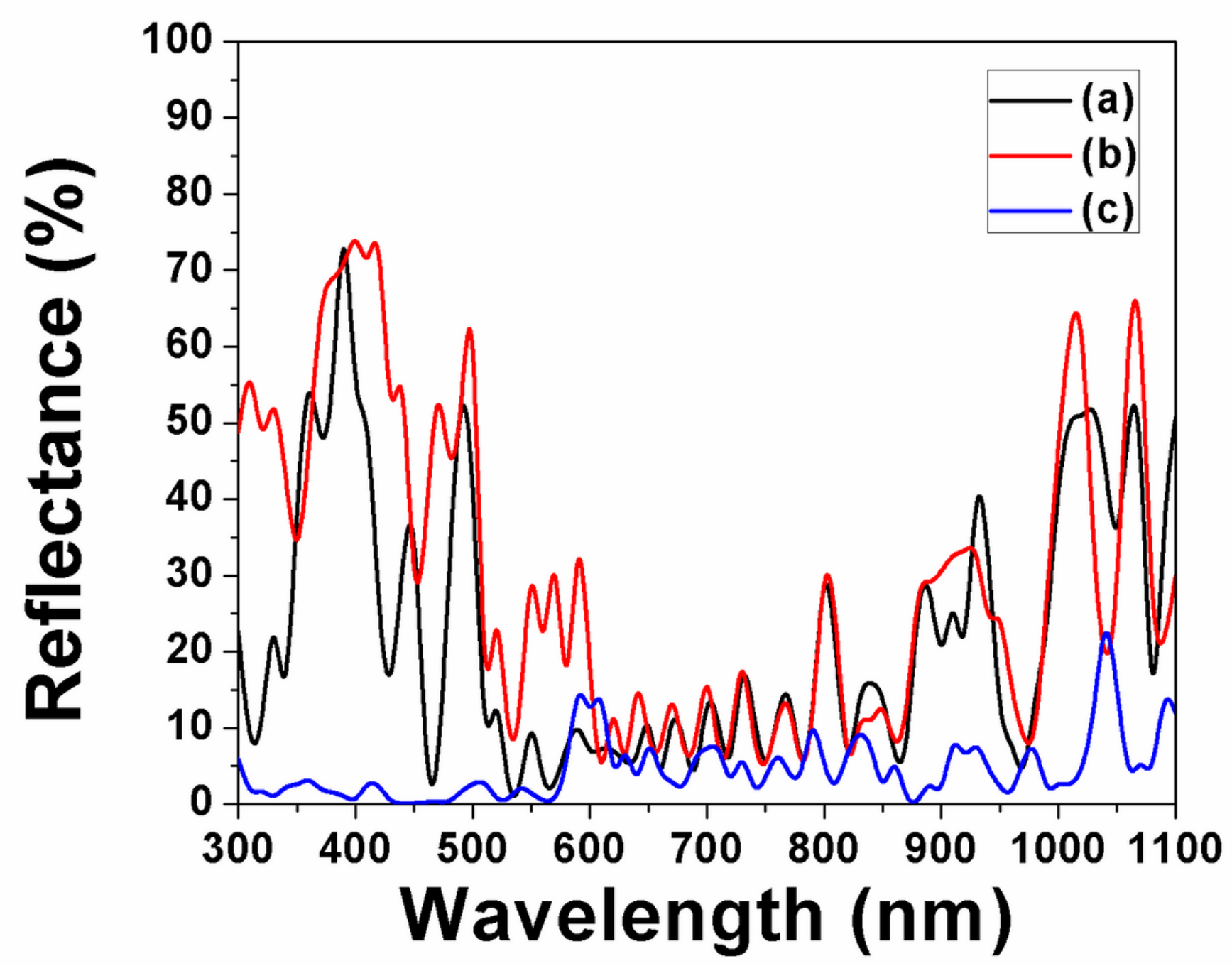

Figure 8

Reflectance profiles of (a) air/ZnO/Si for $0^{\circ}$ angle of incidence (b) air/ZnO/Si with silica nanoparticles for $0^{\circ}$ angle of incidence and (c) air/ZnO/Si and silica nanoparticles for $0^{\circ}$ angle of incidence. 


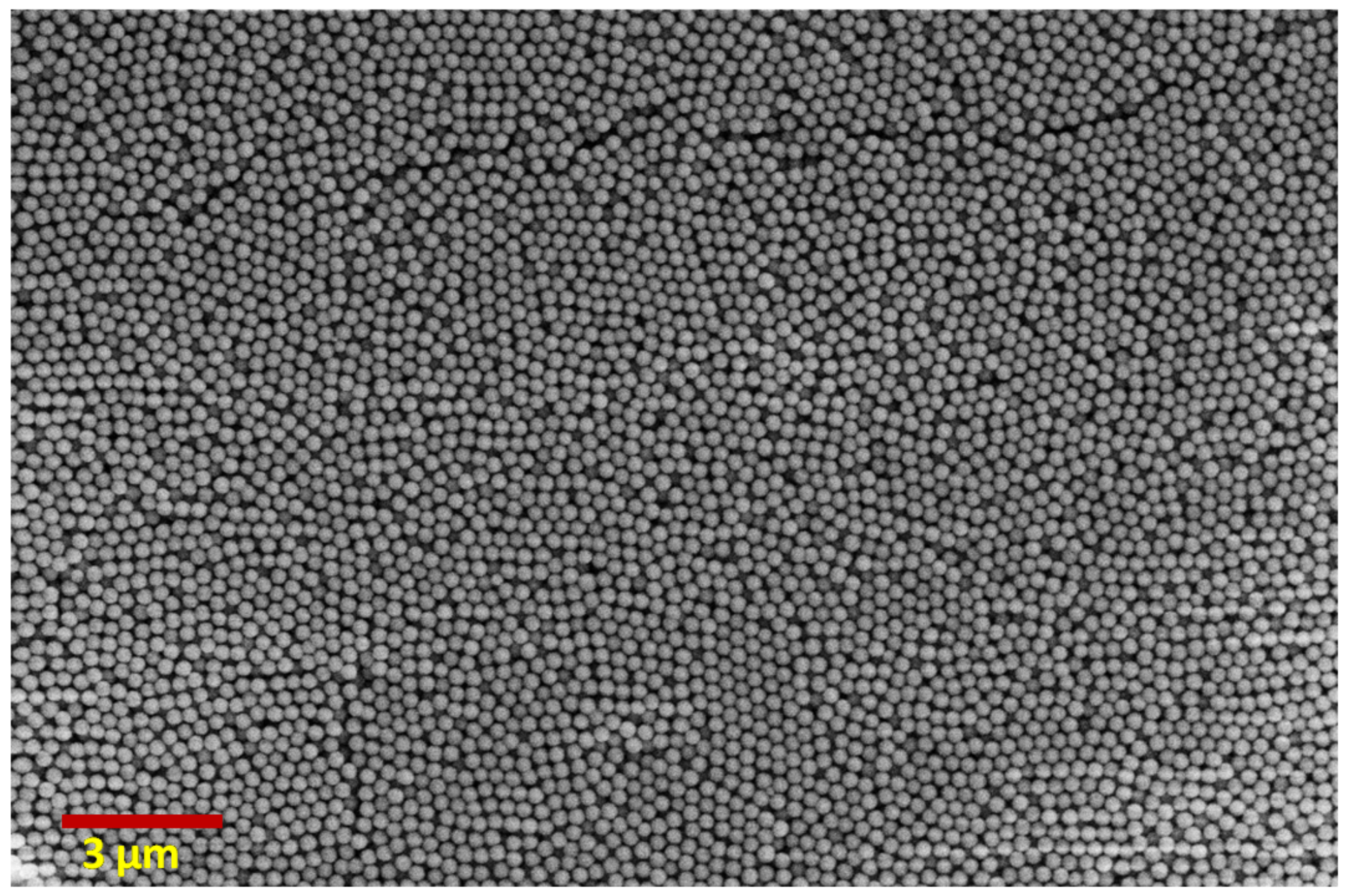

Figure 9

FESEM image (top view) of fabricated silica nanoparticles on top of the thin silicon substrate. 


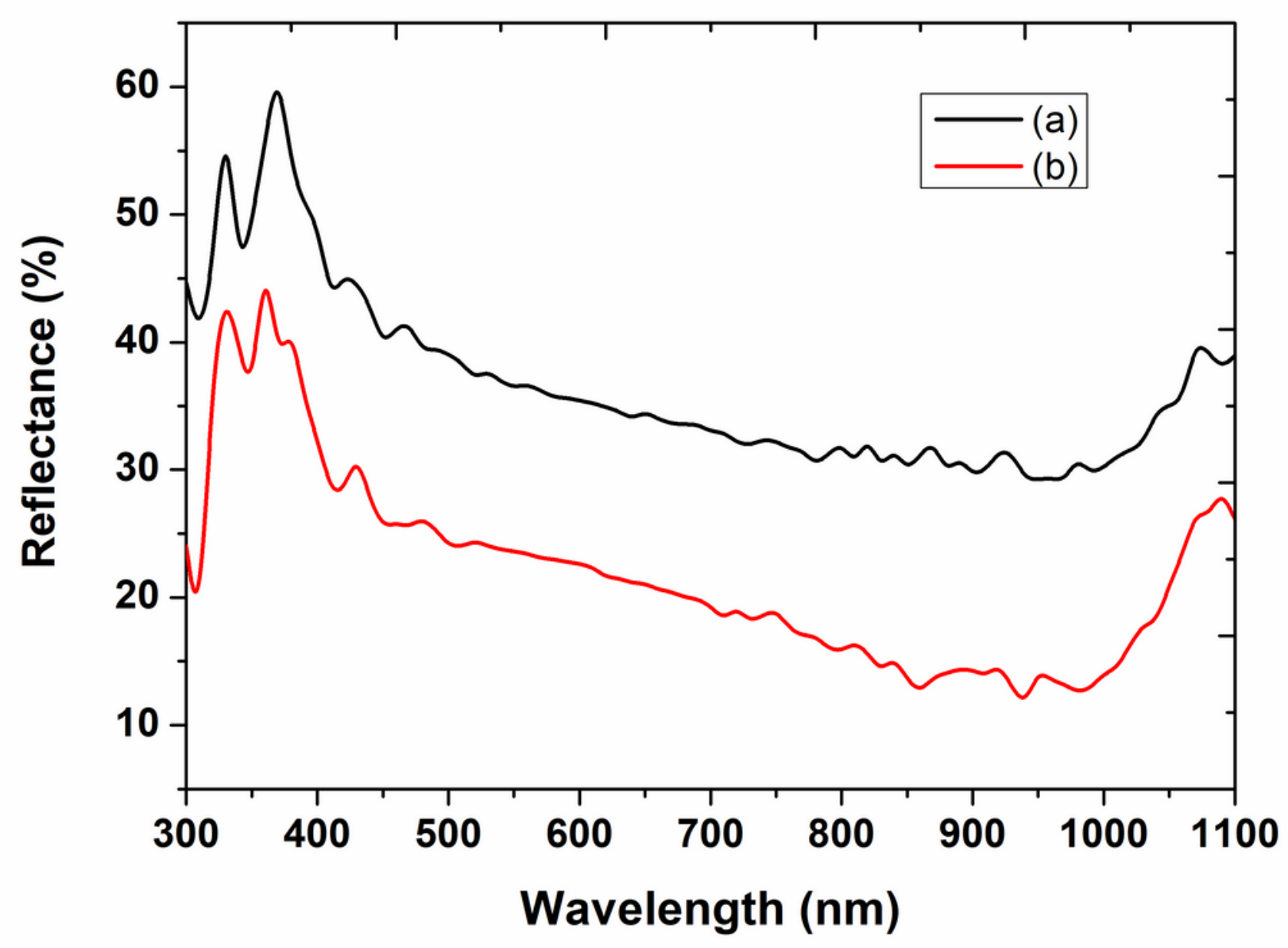

Figure 10

Reflectance curves for (a) bare ultrathin wafer and the same with (b) Silica nanoparticle embedded ZnO layer on top of the ultrathin wafer. 